\title{
Multiobjective Optimal Control of Longitudinal Seismic Response of a Multitower Cable-Stayed Bridge
}

\author{
Geng Fangfang ${ }^{1,2}$ and Ding Youliang ${ }^{1,2}$ \\ ${ }^{1}$ Nanjing Institute of Technology, Nanjing 211167, China \\ ${ }^{2}$ Key Laboratory of Concrete and Prestressed Concrete Structures of Ministry of Education, Southeast University, \\ Nanjing 210096, China
}

Correspondence should be addressed to Ding Youliang; civilchina@hotmail.com

Received 30 March 2016; Accepted 14 June 2016

Academic Editor: Sergio De Rosa

Copyright (C) 2016 G. Fangfang and D. Youliang. This is an open access article distributed under the Creative Commons Attribution License, which permits unrestricted use, distribution, and reproduction in any medium, provided the original work is properly cited.

\begin{abstract}
The dynamic behavior of a multitower cable-stayed bridge with the application of partially longitudinal constraint system using viscous fluid dampers under real earthquake ground motions is presented. The study is based on the dynamic finite element model of the Jiashao Bridge, a six-tower cable-stayed bridge in China. The prime aim of the study is to investigate the effectiveness of viscous fluid dampers on the longitudinal seismic responses of the bridge and put forth a multiobjective optimization design method to determine the optimized parameters of the viscous fluid dampers. The results of the investigations show that the control objective of the multitower cable-stayed bridge with the partially longitudinal constraint system is to yield maximum reductions in the base forces of bridge towers longitudinally restricted with the bridge deck, with slight increases in the base forces of bridge towers longitudinally unrestricted with the bridge deck. To this end, a multiobjective optimization design method that uses a nondominating sort genetic algorithm II (NSGA-II) is used to optimize parameters of the viscous fluid dampers. The effectiveness of the proposed optimization design method is demonstrated for the multitower cable-stayed bridge with the partially longitudinal constraint system, which reveals that a design engineer can choose a set of proper parameters of the viscous fluid dampers from Pareto optimal fronts that can satisfy the desired performance requirements.
\end{abstract}

\section{Introduction}

For long-span cable-stayed bridges, the multitower cablestayed bridges with three or more towers have been a recent design trend [1]. Typical examples of this bridge type are the Millau Viaduct Bridge in France, the Maracaibo Bridge in Venezuela, the Rion-Antirion Bridge in Greece, the Mezcala Bridge in Mexico, the Dongting Lake Bridge in China, and the Ting Kau Bridge in Hong Kong [1]. The longest multitower cable-stayed bridge in the world is Jiashao Bridge in China, which is a six-tower cable-stayed bridge with the total length of $2680 \mathrm{~m}$. Compared with a conventional threespan cable-stayed bridge with two towers, large temperatureinduced deformation in the long bridge deck is one of the major problems in the design of multitower cable-stayed bridges. The commonly used structural measure to reduce the temperature effects is the application of longitudinal constraints between the bridge deck and part of bridge towers such as the Millau Viaduct Bridge in France and the Jiashao Bridge in China. The application of the partially longitudinal constraint system can improve the static performance of the multitower cable-stayed bridge under temperature action. However, studies of the seismic performance of the multitower cable-stayed bridge using partially longitudinal constraint system under earthquake ground motions are meager. In addition, it is especially desirable to provide a seismic control scheme for the multitower cable-stayed bridge using partially longitudinal constraint system.

To date, an amount of research work had been done on investigating the seismic performance of two-tower cablestayed bridges using different longitudinal constraint systems between the bridge deck and towers [2,3]. These studies had shown that the fully floating constraint system with rigid connections between all bridge towers and the deck will 


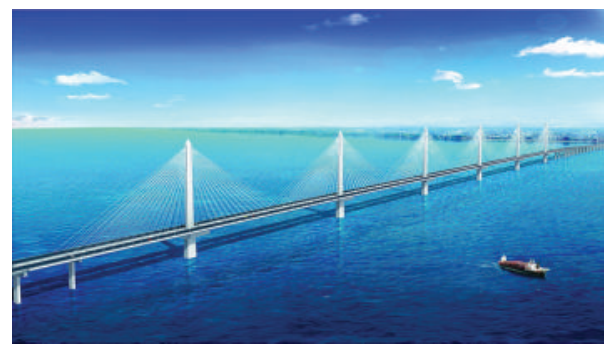

(a) View of Jiashao Bridge

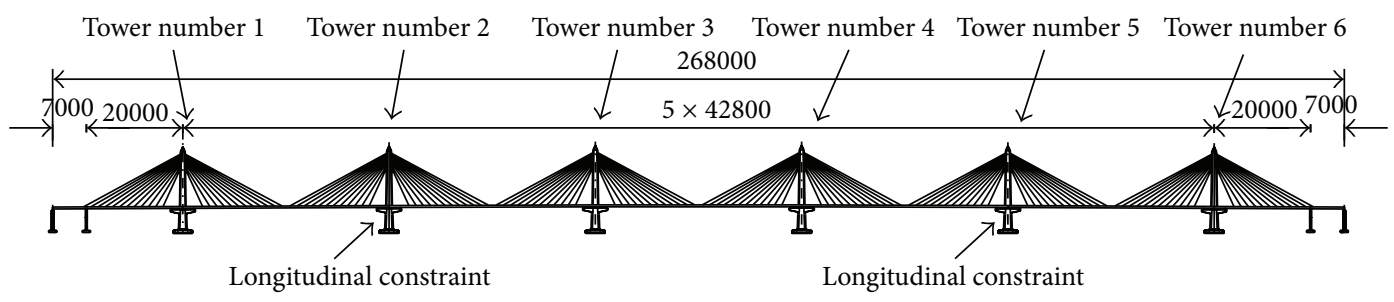

(b) Elevation of Jiashao Bridge (unit: $\mathrm{cm}$ )

FIgURE 1: Jiashao Bridge.

reduce the displacements of the bridge deck and significantly increase the base shears and moments of towers. On the other hand, the displacements of the bridge deck will be excessive if the fully floating system with no connections between all towers and the deck is used. Considering the fact that the safety of bridge towers is vital to the cable-stayed bridges, the fully floating system is widely used in long-span two-tower cable-stayed bridges recently. In order to reduce the large displacements of the bridge deck in the fully floating system, various seismic control methods for the two-tower cablestayed bridges had been investigated in detail by various researchers such as passive control [4], active control $[5,6]$, active and passive control [7], semiactive control [8], negative stiffness control $[9,10]$, and hybrid control [11]. Among these seismic control methods, passive dampers have attracted the particular attention of structural control engineers due to their reliability and ease of implementation. Previous investigations have demonstrated the effectiveness of passive dampers in reducing the seismic responses of two-tower cable-stayed bridges [12]. Therefore, it would be interesting to investigate the application of passive dampers such as viscous fluid dampers in reducing the seismic responses of a multitower cable-stayed bridge using partially longitudinal constraint system.

This paper investigates the performance of viscous fluid dampers for the earthquake protection of a multitower cable-stayed bridge with the application of partially longitudinal constraint system under strong earthquake ground motions. The specific objectives of this study are to (i) make a comparison of the longitudinal seismic responses of a multitower cable-stayed bridge using partially longitudinal constraint system and fully floating system, (ii) investigate the differences in the seismic control effects using viscous fluid dampers for a multitower cable-stayed bridge with partially longitudinal constraint system and fully floating system, and (iii) put forth a multiobjective optimization design method to determine the optimized parameters of the viscous fluid dampers for seismic control of the multitower cable-stayed bridge with the partially longitudinal constraint system.

\section{Longitudinal Seismic Response of a Multitower Cable-Stayed Bridge}

2.1. Bridge Description. The subject of this study is Jiashao Bridge shown in Figure 1(a), which is a six-tower cable-stayed bridge that crosses the Hangzhou Bay along the highway between Jiaxing and Shaoxing in China [13]. The total length of the bridge is $2680 \mathrm{~m}$ with the span arrangement of $70 \mathrm{~m}$ $+200 \mathrm{~m}+5 \times 428 \mathrm{~m}+200 \mathrm{~m}+70 \mathrm{~m}$, which is the longest multispan cable-stayed bridge in the world. Figure 1(b) shows the design elevation view of the Jiashao Bridge. In order to overcome the problem of large temperature deformation in the long bridge deck, the partially longitudinal constraint system is applied in the design of Jiashao Bridge. As shown in Figure 1(b), the longitudinal constraints are applied to restrict the bridge deck from moving in the longitudinal direction at bridge towers number 2 and number 5, respectively. And there have been no longitudinal constraints between the bridge deck and other bridge towers. The role of such partially longitudinal constraint system is to reduce the temperatureinduced longitudinal deformation in the bridge deck.

2.2. Finite Element Model. A three-dimensional finite element model of the Jiashao Bridge has been developed by use of the commercial software package ANSYS [13]. The finite element model involves 1402 nodes and 1872 elements, as shown in Figure 2. In this model, a double-girder model is used to simulate the bridge deck system when conducting dynamic analysis. The bridge deck, bridge towers, and piers are all modeled as Timoshenko's beam elements with 6 degrees of freedom (DOFs) at each node, which account 


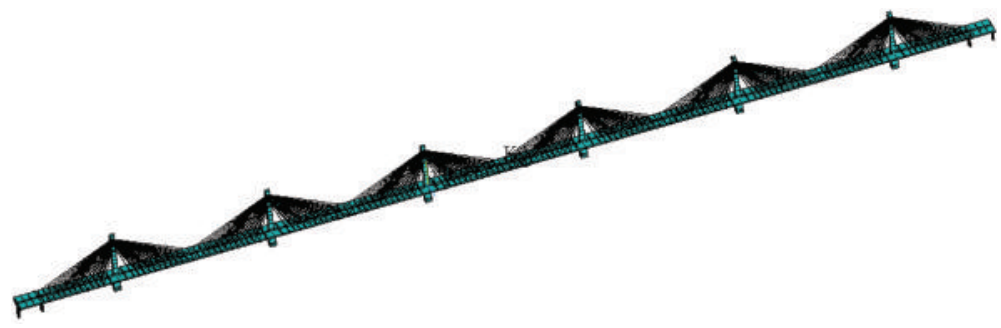

Figure 2: Finite element model of Jiashao Bridge.

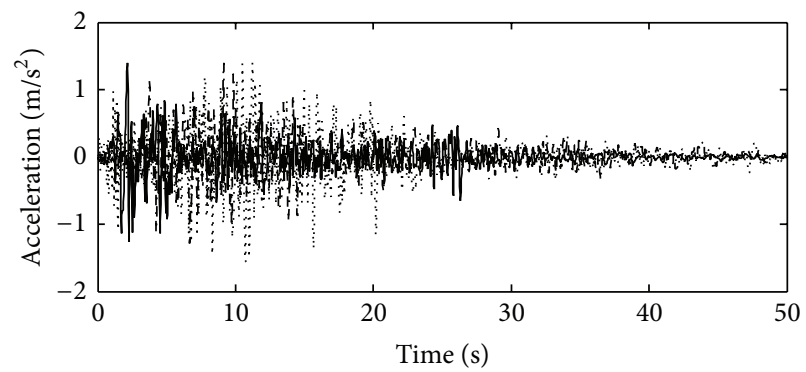

- DZ1
$. \cdots-$ DZ2
…. DZ3

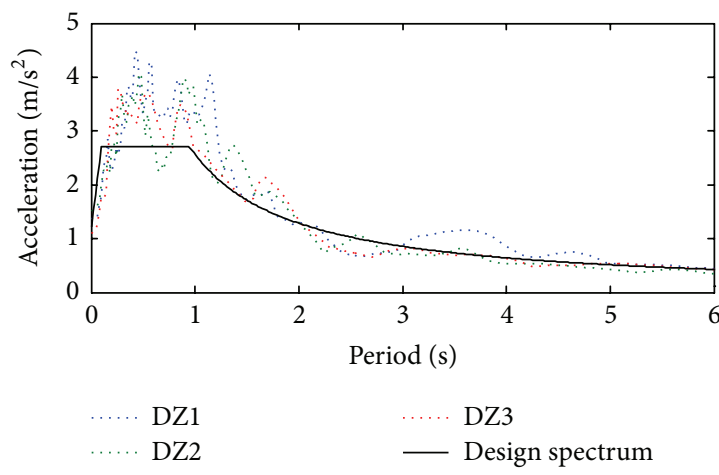

(b) Acceleration response spectra

(a) Time-history curves

FIGURE 3: Time-history curves and acceleration response spectra of earthquake ground motions.

for transverse shear deformation, biaxial bending, and axial strain. A 2-node truss element is used to simulate the stay cables, which accounts for only tension and no compression based on the real condition. Considering the geometric stiffness of stay cables under dead loadings, the equivalent elastic modulus for stay cables proposed by Ernst is adopted. Constraints are applied to restrict the bridge deck from moving in the lateral and vertical directions at all bridge towers and in the longitudinal direction at bridge towers number 2 and number 5 . Boundary conditions restrict the motions of bridge deck at all bridge piers to allow only longitudinal displacement $X$ and rotations about $y$-axis and $z$-axis. Additionally, the bridge is assumed to be attached to bedrock, and the effects of soil-structure interactions are neglected.

2.3. Longitudinal Seismic Response of the Bridge. The longitudinal seismic responses of the multitower cable-stayed bridge are investigated under three different real earthquake ground motions. The time-history curves of three earthquake ground motions (DZ1, DZ2, and DZ3) are shown in Figure 3(a), in which the peak ground acceleration of selected earthquake ground motions is adjusted to $0.1392 \mathrm{~g}$ according to seismic risk analysis of the bridge site. The corresponding acceleration response spectra of the ground motions for a $2 \%$ damping ratio are shown in Figure 3(b). The seismic design spectrum is also shown in Figure 3(b), which is in accordance with the acceleration response spectra of the real earthquake ground motions. One-dimensional ground
TABLE 1: Peak displacements at two ends of the bridge deck.

\begin{tabular}{lcc}
\hline $\begin{array}{l}\text { Peak } \\
\text { displacement }\end{array}$ & $\begin{array}{c}\text { Partially longitudinal } \\
\text { constraint system }\end{array}$ & Fully floating system \\
\hline Left end $(\mathrm{m})$ & 0.1586 & 0.7023 \\
Right end $(\mathrm{m})$ & 0.1589 & 0.7025 \\
\hline
\end{tabular}

acceleration is assumed to act uniformly at all the supports along the longitudinal direction of the bridge. The maximum results from calculation results of three earthquake ground motions are selected to evaluate the seismic performance of the multitower cable-stayed bridge.

To evaluate the seismic performance of the multitower cable-stayed bridge with the application of partially longitudinal constraint system, the longitudinal response quantities selected are the peak base shear of the bridge tower, the peak base moment of the bridge tower, the peak displacement at the end of the bridge deck, and peak displacement on the top of the bridge tower. Figure 4 shows the peak base shears and moments of bridge towers. Figure 5 shows peak displacements on the top of bridge towers. Table 1 shows the peak displacements at two ends of the bridge deck. In order to investigate the effect of partially longitudinal constraints on the seismic responses of the bridge, the contrast analytical model is developed based on the original finite element model of Jiashao Bridge. In the contrast model, the longitudinal constraints between the bridge deck and all six towers are released in the bridge, that is, fully floating system. The seismic responses of the contrast model with fully floating 


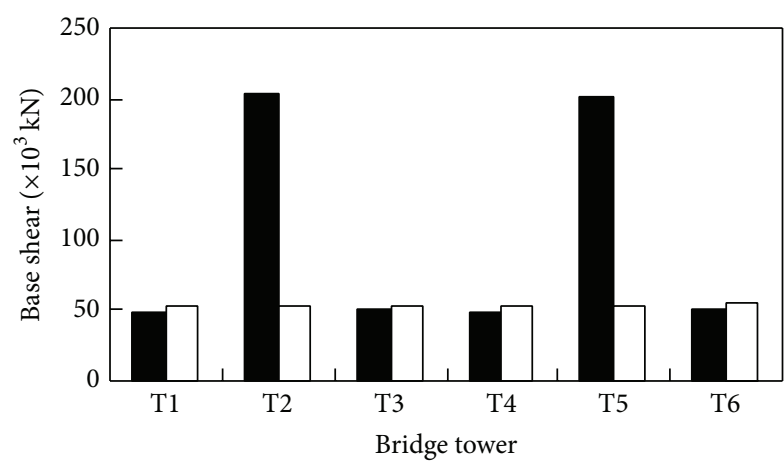

Partially longitudinal constraint system Fully floating system

(a) Peak base shear

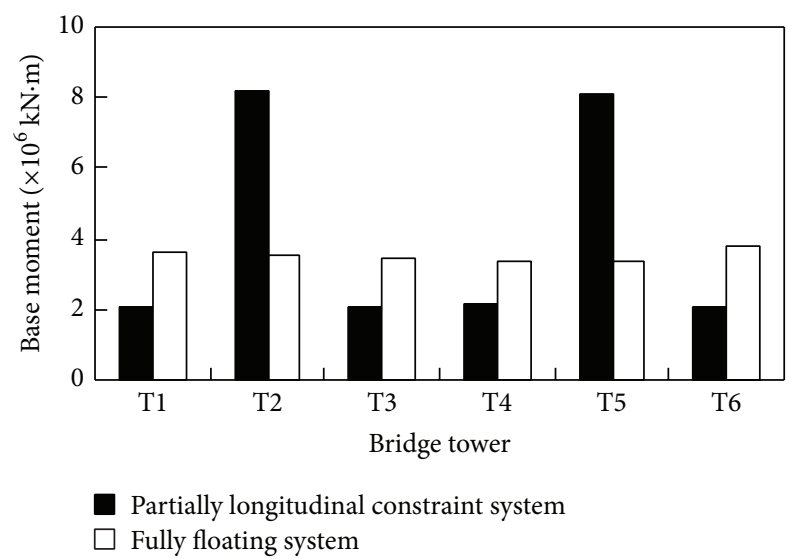

(b) Peak base moment

Figure 4: Peak base shears and peak base moments of bridge towers.

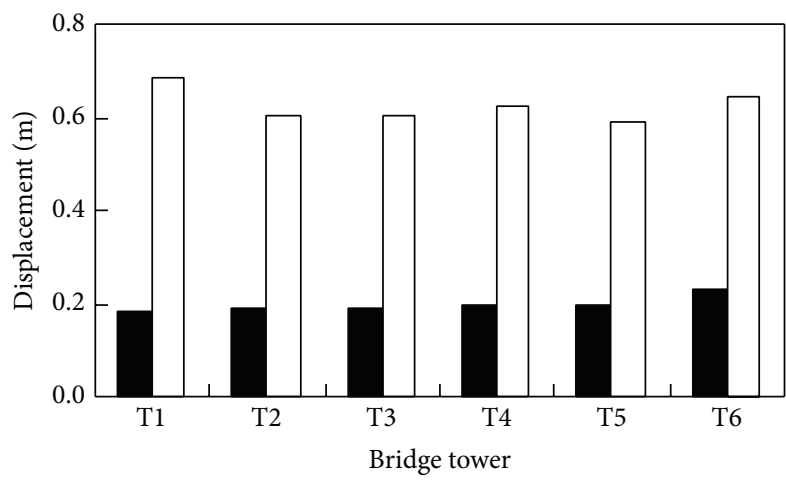

Partially longitudinal constraint system $\square$ Fully floating system

Figure 5: Peak displacements on the top of bridge towers.

system are also calculated and shown in Figures 4 and 5 and Table 1.

It can be seen from Figures 4 and 5 and Table 1 that the peak base shears and moments of the bridge towers number 2 and number 5 in the partially longitudinal constraint system are 4 times as those in the other towers. Thus, part of bridge towers longitudinally restricted with the bridge deck results in the concentration effects of base shear and moment. In contrast, the peak base shears and moments of all towers are relatively small and uniformly distributed in the fully floating system. It can also be seen that the peak displacements on the top of bridge towers and the peak displacements at two ends of bridge deck in the fully floating system are around 3 times and 4.5 times as those in the partially longitudinal constraint system, respectively. This is because the longitudinal floating vibration mode disappears in the partially longitudinal constraint system, which leads to the small displacements of the bridge deck and towers.

Therefore, the advantages of the multitower cable-stayed bridge with the application of partially longitudinal constraint system are that the peak displacements of the bridge deck and towers are very small and the peak base shears and moments of those towers which are longitudinally unrestricted with the bridge deck are also small. However, the disadvantage is that the peak base shears and moments of those towers longitudinally restricted with the bridge deck are too large. Therefore, the control objective of the partially longitudinal constraint system is to reduce the peak base shears and moments of bridge towers longitudinally restricted with the bridge deck, which is very different from the fully floating system. In the fully floating system, the peak displacements of the bridge deck and towers are too large. In contrast, the peak base shears and moments of all towers are relatively small. Hence, the control objective of the fully floating system is to reduce the peak displacements of the bridge deck and towers.

\section{Performance of Viscous Fluid Damper for Seismic Control of the Bridge}

3.1. Parametric Study on Viscous Fluid Damper. In this section, a parametric study is performed to investigate the effects of viscous fluid dampers on the seismic control of the multitower cable-stayed bridge with the application of partially longitudinal constraint system. In a viscous fluid damper, the damping force $f$ is described as [14]

$$
f=c|v|^{\alpha} \operatorname{sgn}(v),
$$

where $c$ is the damping coefficient of the damper; $\alpha$ is the velocity exponent of the damper; $v$ is the relative velocity across the damper. From (1), the damping coefficient and the velocity exponent are the two parameters that govern the selection of a viscous fluid damper. In the present study, the velocity exponent $\alpha$ is varied from 0.2 to 1.0 with the interval of 0.2. And the damping coefficient $c$ is varied from 2000 to 16000 with the interval of 2000 . Considering the configuration of the multitower cable-stayed bridge with the partially longitudinal constraint system, the viscous fluid dampers are placed at the bridge towers longitudinally unrestricted with the bridge deck, that is, towers number 1 , number 3 , number 4, and number 6 in Jiashao Bridge, as shown in Figure 6. 


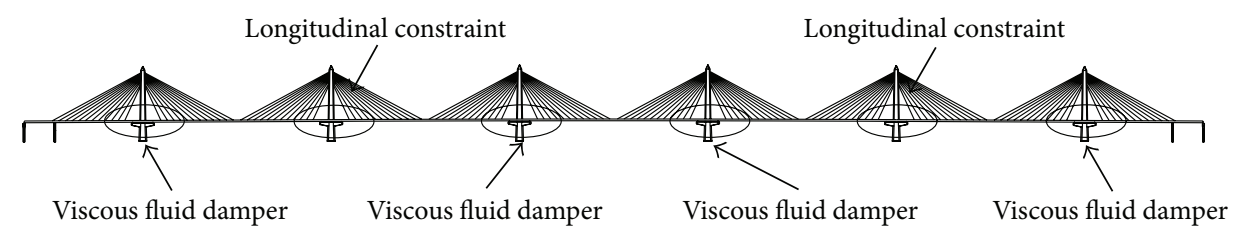

FIGURE 6: Installation of viscous fluid dampers in the bridge.

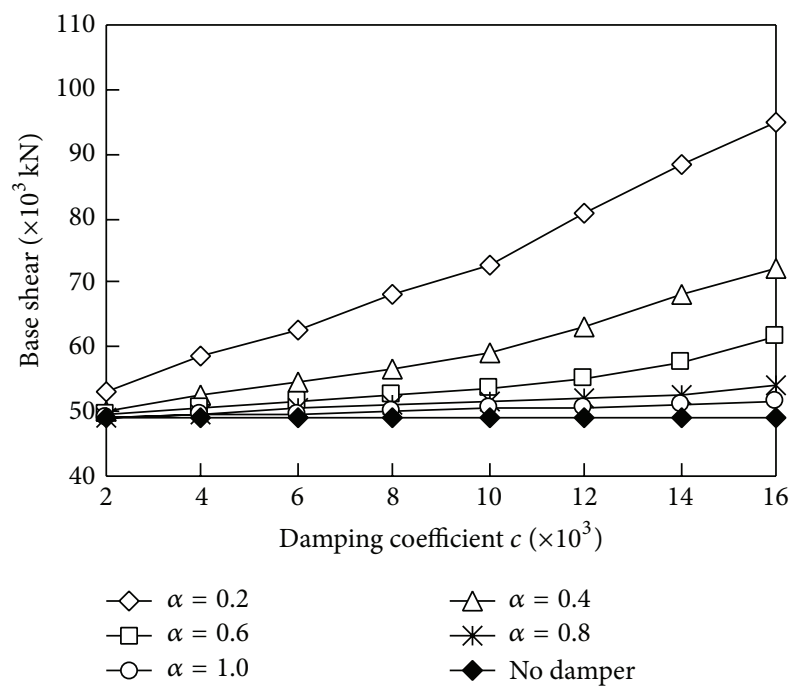

(a) Peak base shear of tower number 1

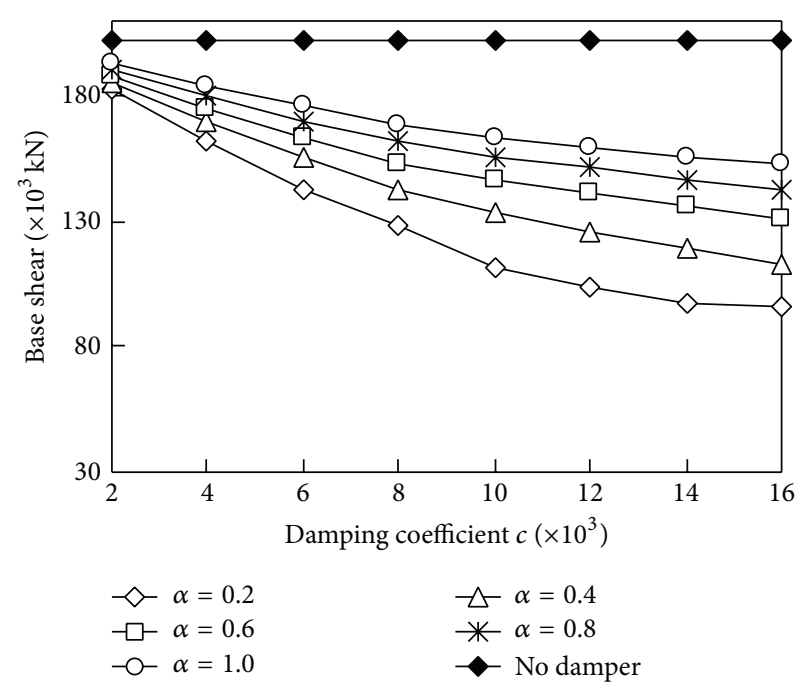

(b) Peak base shear of tower number 2

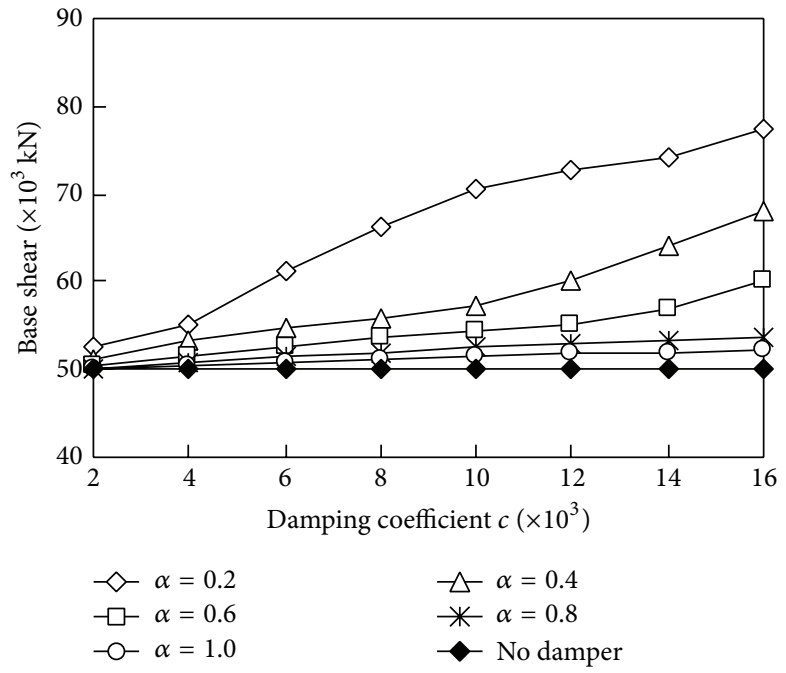

(c) Peak base shear of tower number 3

FIGURE 7: Effects of variations in damping coefficient and velocity exponent of the viscous fluid dampers on the peak base shears of bridge towers.

A parametric study is performed to investigate the effects of variations in damping coefficient $c$ and velocity exponent $\alpha$ of viscous fluid dampers on the seismic responses of the bridge. The results of the parametric study are shown in Figures 7-10. Figures 7 and 8 show the peak base shears and moments of the bridge towers controlled by viscous fluid damper. From Figures 7 and 8, we can see the following: (i) For all the velocity exponents $\alpha$, the peak base shear and moment of the bridge tower number 2 reduce reasonably with increasing damping coefficient $c$ of the viscous fluid dampers. For a specific damping coefficient $c$, the peak base shear and moment of the bridge tower number 2 reduce with decreasing in velocity exponents $\alpha$. For the values of damping coefficient $c=16000$ and velocity exponents $\alpha=0.2$, 


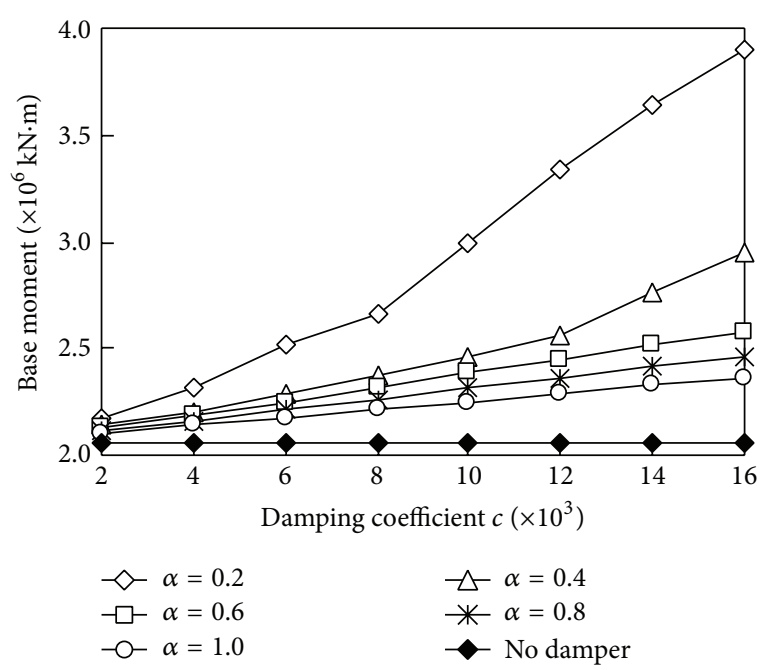

(a) Peak base moment of tower number 1

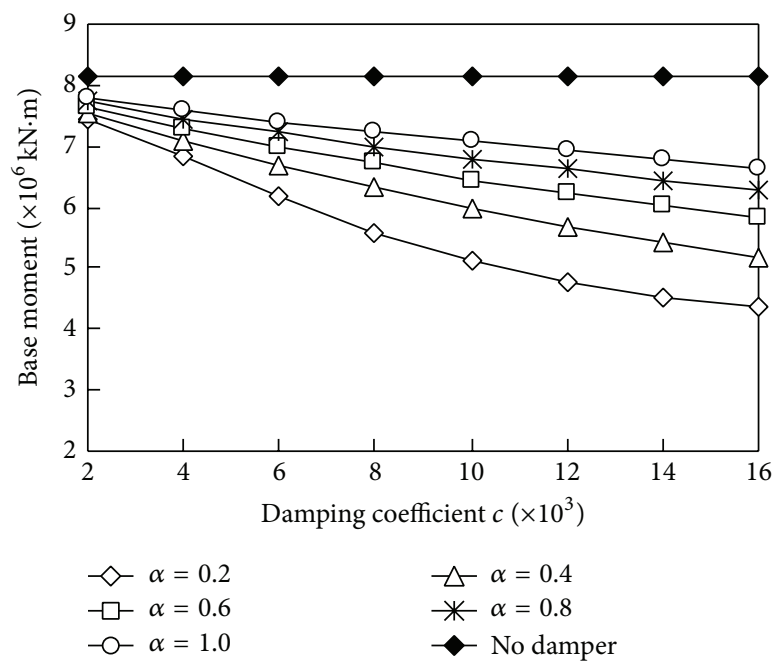

(b) Peak base moment of tower number 2

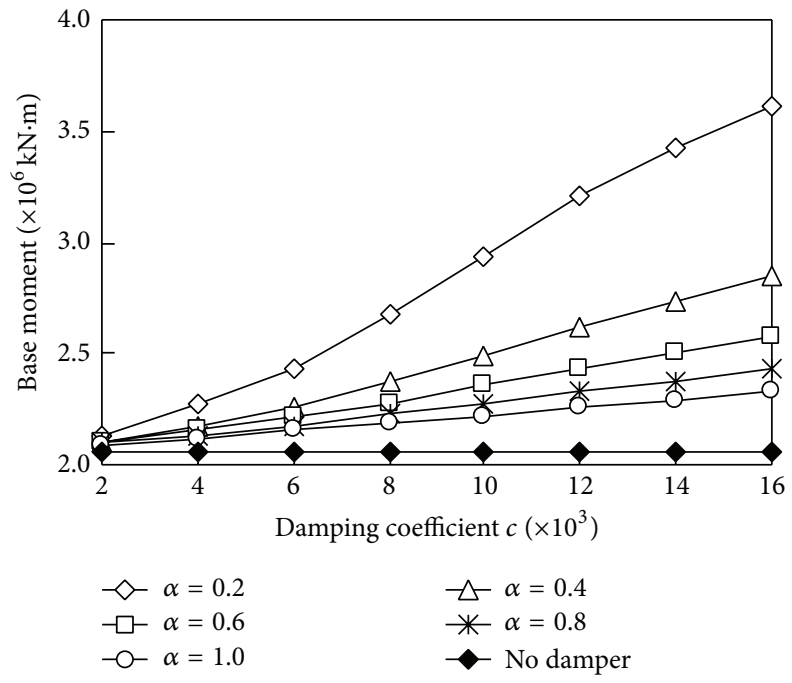

(c) Peak base moment of tower number 3

FIGURE 8: Effects of variations in damping coefficient and velocity exponent of the viscous fluid dampers on the peak base moments of bridge towers.

the reductions observed in the base shear and moment of tower number 2 are $53 \%$ and $47 \%$, respectively.

(ii) For all the velocity exponents $\alpha$, the peak base shears and moments of the bridge towers number 1 and number 3 increase with increasing in damping coefficient $c$. For a specific damping coefficient $c$, the peak base shears and moments of the bridge towers number 1 and number 3 increase reasonably with decreasing in velocity exponents $\alpha$. For the values of damping coefficient $c=16000$ and velocity exponents $\alpha=0.2$, the increases observed in the base shears of towers number 1 and number 3 are $92 \%$ and $55 \%$, respectively. And the increases observed in the base moments of towers number 1 and number 3 are $90 \%$ and $75 \%$, respectively. Therefore, for the partially longitudinal constraint system, the control effects for the base shears and moments of bridge towers are approximately the same due to the small peak displacements on the top of bridge towers.

Figures 9 and 10 show the peak displacements on the top of bridge towers and peak displacements at two ends of bridge deck controlled by viscous fluid dampers. From Figures 9 and 10, we can observe the following:

(i) With regard to the bridge tower number 1 , the peak displacement on the top of the tower reduces with an increase in damping coefficient $c$ up to a certain level for the velocity exponents $\alpha=0.2$ and 0.4 . The maximum reduction in the peak displacement of bridge tower number 1 is around $6 \%$. With regard to the bridge tower number 2 , the peak displacement on the top of the tower reduces with an increase in damping coefficient $c$ up to a certain level for 

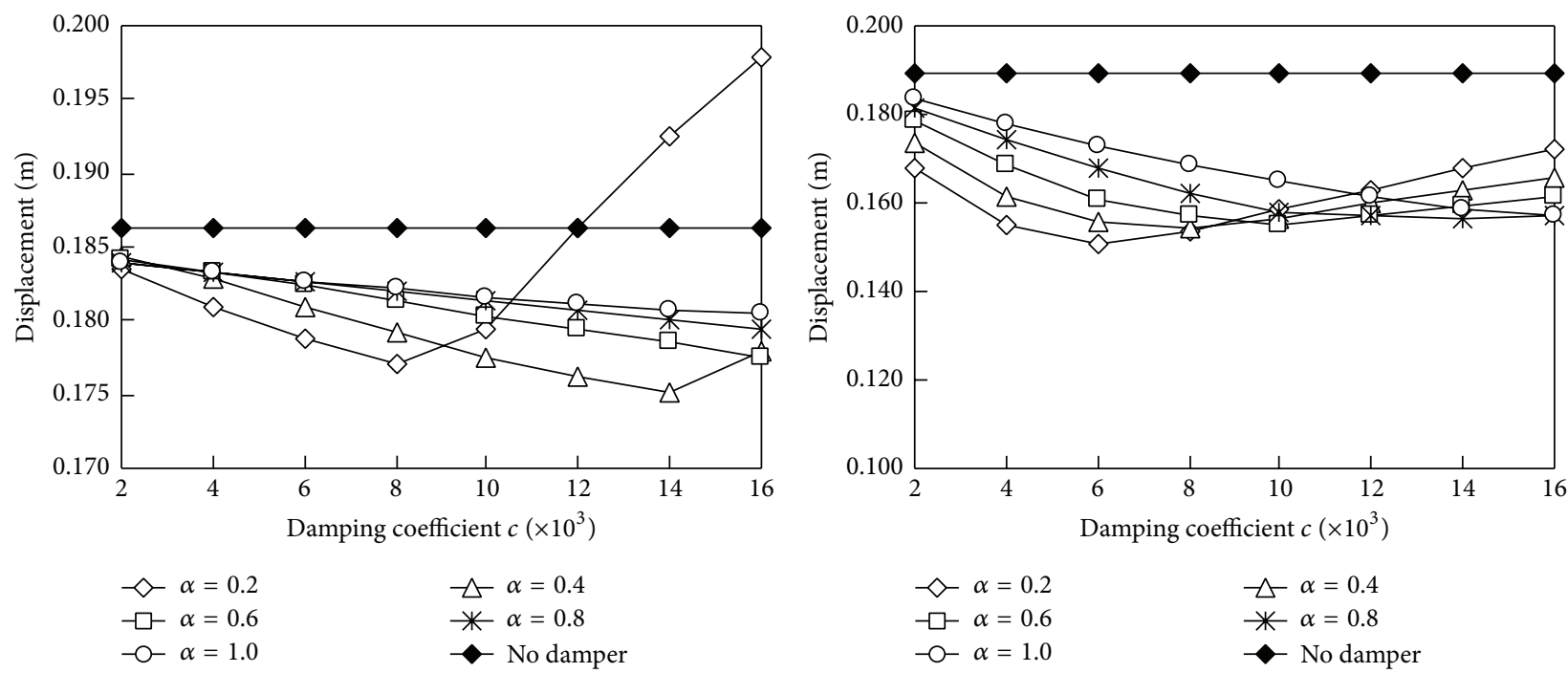

$$
\begin{aligned}
& \begin{array}{llrl}
\prec \alpha=0.2 & \neg-\alpha=0.4 \\
\neg-\alpha=0.6 & \quad * \alpha=0.8
\end{array} \\
& \multimap-\quad \multimap \text { No damper }
\end{aligned}
$$

(a) Peak displacement of tower number 1

(b) Peak displacement of tower number 2

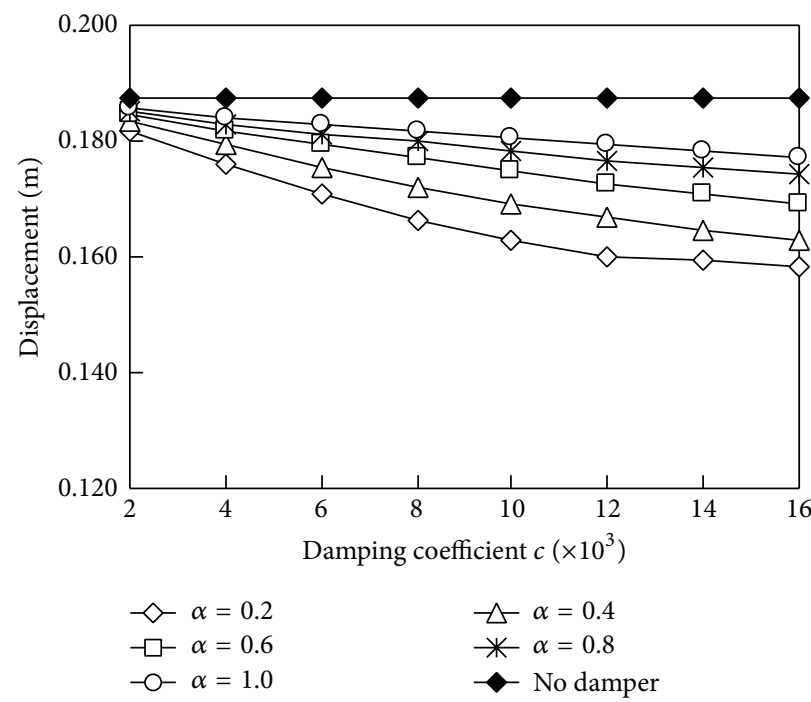

(c) Peak displacement of tower number 3

FIGURE 9: Effects of variations in damping coefficient and velocity exponent of the viscous fluid dampers on the peak displacements on the top of bridge towers.

the velocity exponents $\alpha=0.2,0.4,0.6$, and 0.8 . The maximum reduction in the peak displacement of bridge tower number 1 is around $20 \%$. With regard to the bridge tower number 3 , the peak displacement on the top of the tower reduces with an increase in damping coefficient $c$. For the values of damping coefficient $c=16000$ and velocity exponent $\alpha=0.2$, the reduction observed in the peak displacement of bridge tower number 3 is around $16 \%$.

(ii) For the velocity exponents $\alpha=0.6,0.8$, and 1.0, the peak displacements at two ends of the bridge deck increase with increasing in damping coefficient c. And for the velocity exponents $\alpha=0.2$ and 0.4 , the peak displacements of bridge deck increase with an increase in damping coefficient $c$ up to a certain level, giving maximum values for the peak displacements of bridge deck. The maximum increase in the peak displacements of bridge deck is around $21 \%$, which corresponds to the parameters of damping coefficient $c=12000$ and velocity exponents $\alpha=0.4$.

The analytical investigations for the seismic control of the multitower cable-stayed bridge with the partially longitudinal constraint system using viscous fluid dampers indicate that the large base shears and moments of bridge towers longitudinally restricted with the bridge deck are significantly reduced, with significant increases in the base shears and moments of bridge towers longitudinally unrestricted with the bridge deck. Furthermore, the displacements on the top of bridge towers are found to be slightly reduced, with slight increases in the displacements at two ends of bridge deck. 


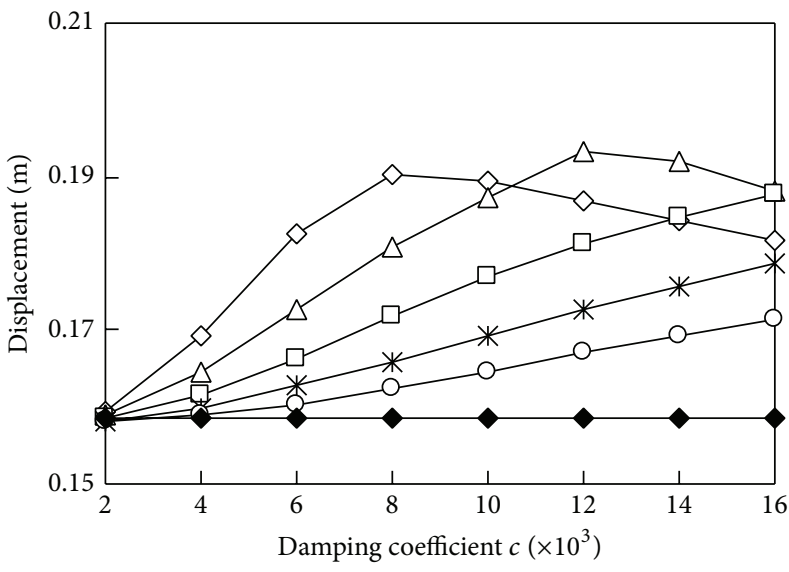

$$
\begin{aligned}
& \checkmark \alpha=0.2 \\
& \neg-\alpha=0.6 \\
& -0-\alpha=1.0 \\
& \triangle \alpha=0.4 \\
& \text { * } \alpha=0.8 \\
& \text { - No damper }
\end{aligned}
$$

(a) Peak displacement at the left end of bridge deck

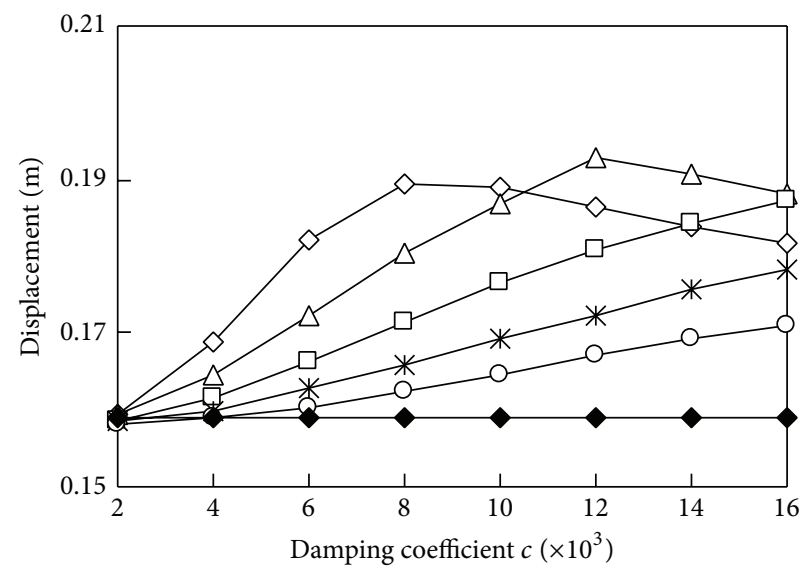

$$
\begin{aligned}
& \checkmark \alpha=0.2 \\
& \neg-\alpha=0.6 \\
& -0-\alpha=1.0 \\
& \begin{array}{l}
\smile \alpha=0.4 \\
* \alpha=0.8 \\
\multimap \text { No damper }
\end{array}
\end{aligned}
$$

(b) Peak displacement at the right end of bridge deck

FIGURE 10: Effects of variations in damping coefficient and velocity exponent of the viscous fluid dampers on the peak displacements at two ends of bridge deck.

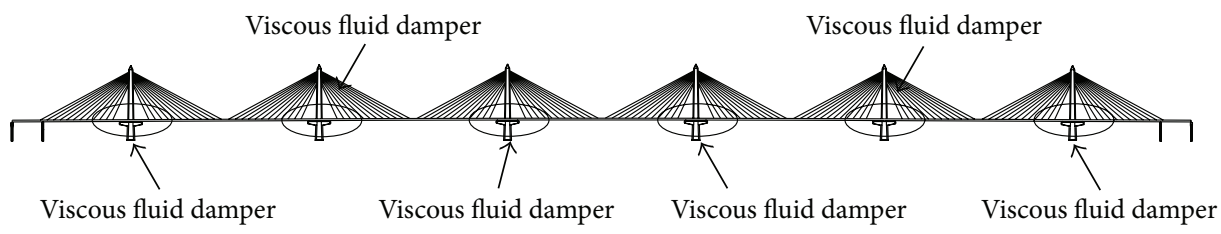

FIGURE 11: Installation of viscous fluid dampers in the fully floating system.

3.2. Discussion. In order to investigate the effect of partially longitudinal constraints on the seismic control of the multitower cable-stayed bridge, a parametric study is further performed for seismic control of the contrast model with fully floating system. In the fully floating system, the viscous fluid dampers are placed at all of bridge towers, that is, towers number 1 , number 2 , number 3 , number 4 , number 5 , and number 6, as shown in Figure 11. The results of the parametric study for the fully floating system are shown in Figure 12. It should be noted that the peak base shears and moments of all towers are uniformly distributed in the fully floating system and the seismic control effects using viscous fluid dampers for all bridge towers are approximately the same. Hence, only the seismic control results of the bridge tower number 3 are shown in Figure 12 for the sake of brevity.

Figures 12(a) and 12(b) show the peak base shear and moment of the bridge tower number 3 controlled by viscous fluid damper. From Figure 12(a), it can be seen that, for all the velocity exponents $\alpha$, the peak base shear of the bridge tower number 3 increases with increasing in damping coefficient $c$. For a specific damping coefficient $c$, the peak base shear of the bridge tower number 3 increases reasonably with decreasing in velocity exponents $\alpha$. For the values of damping coefficient $c=16000$ and velocity exponents $\alpha=0.2$, the increase observed in the base shear of tower number 3 is around $49 \%$. From Figure 12(b), it can be seen that the peak moment of the bridge tower number 3 reduces with an increase in damping coefficient $c$ up to a certain level for the velocity exponents $\alpha=0.2,0.4$, and 0.6 . And for the velocity exponents $\alpha=0.8$ and 1.0, the peak moment of the bridge tower number 3 reduces with increasing in damping coefficient $c$. The maximum reduction in the peak moment of the bridge tower number 3 is around $32 \%$.

Figures $12(\mathrm{c})$ and $12(\mathrm{~d})$ show the peak displacement on the top of bridge tower number 3 and peak displacement at the left end of bridge deck controlled by viscous fluid dampers. It can be observed from Figures 12(c) and 12(d) that, for all the velocity exponents $\alpha$, the peak displacement on the top of bridge tower number 3 and peak displacement at the left end of bridge deck both reduce with increasing in damping coefficient $c$. The maximum reductions in the peak displacement on the top of bridge tower number 3 and peak displacement at the left end of bridge deck are around $78 \%$ and $74 \%$, respectively.

The analytical investigations for the seismic control of the multitower cable-stayed bridge with the fully floating system using viscous fluid dampers indicate that the large displacements on the top of bridge towers and large displacements at two ends of bridge deck can be significantly reduced using viscous fluid dampers. And the base moments of bridge towers are found to be also reduced reasonably, with increases in the base shears of bridge towers. Therefore, the seismic 

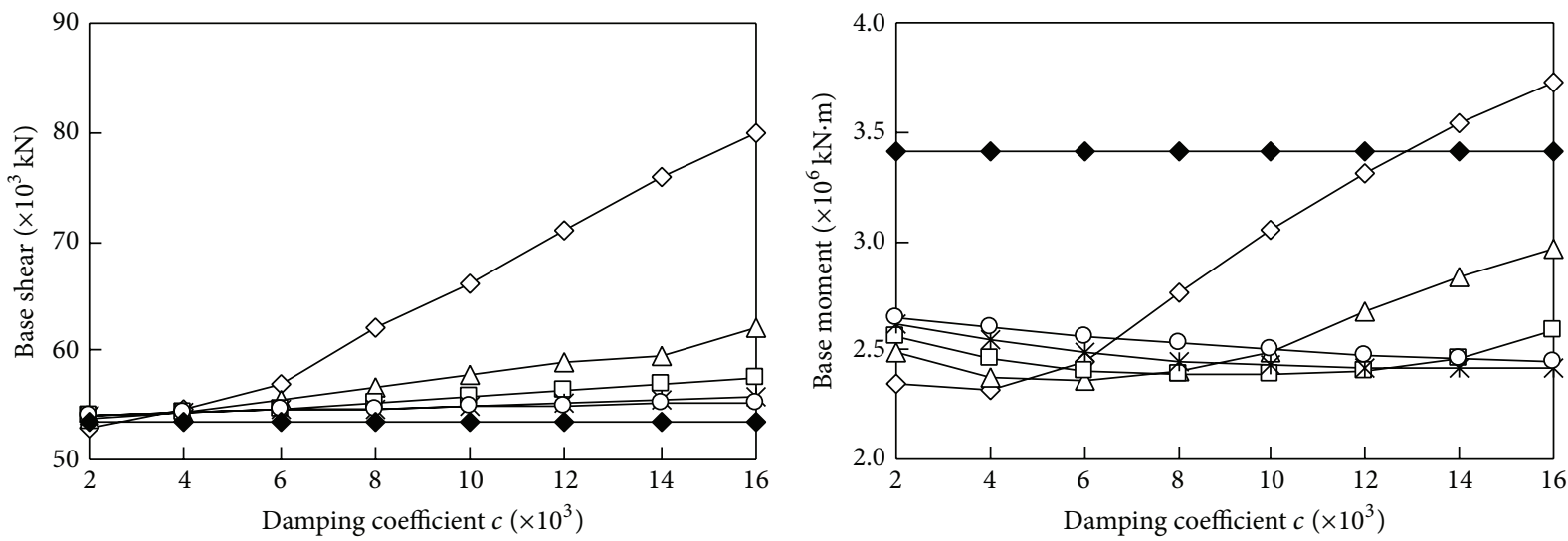

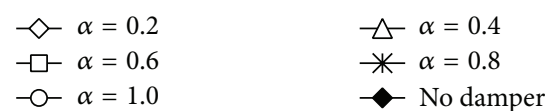

(a) Peak base shear of tower number 3

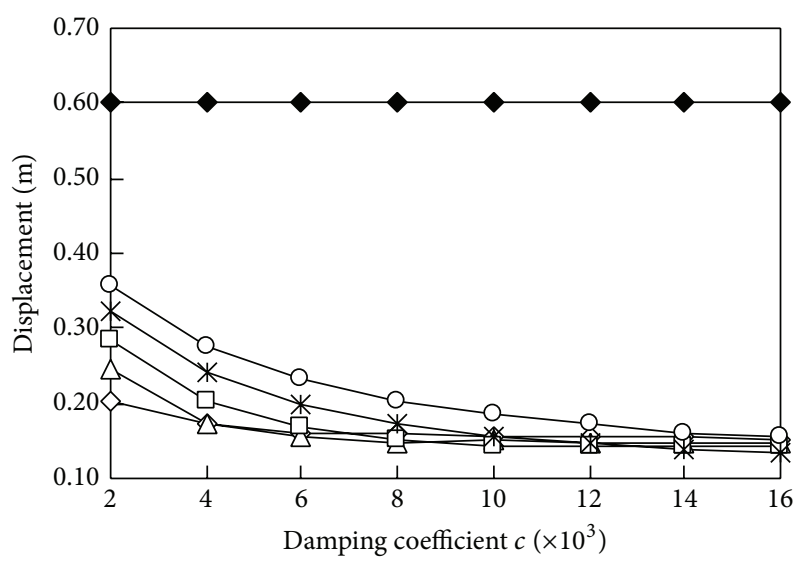

$$
\begin{aligned}
& \checkmark \alpha=0.2 \\
& -\square-\alpha=0.6 \\
& -0-\alpha=1.0 \\
& \neg \alpha=0.4 \\
& \text { * } \alpha=0.8
\end{aligned}
$$

(b) Peak base moment of tower number 3

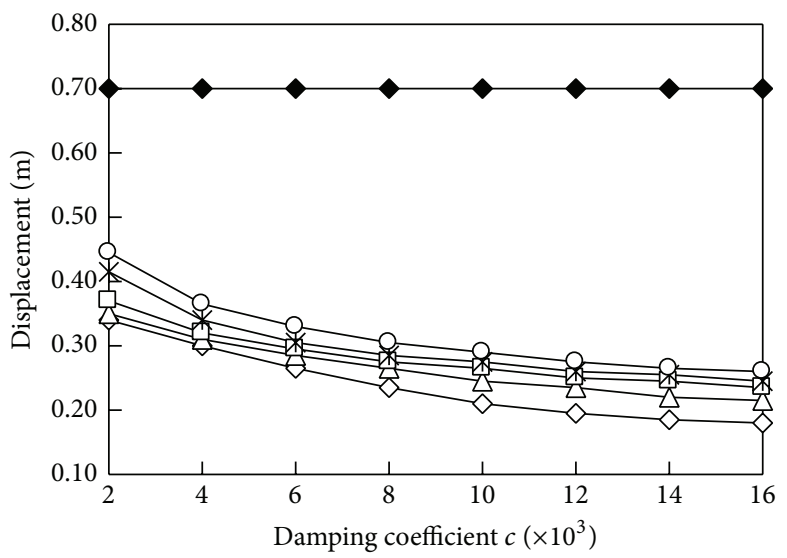

$$
\begin{array}{ll}
\prec \alpha=0.2 & -\checkmark \alpha=0.4 \\
\multimap-\alpha=0.6 & \multimap \alpha=0.8 \\
\multimap-\alpha=1.0 & \multimap \text { No damper }
\end{array}
$$

(d) Peak displacement at the left end of bridge deck

(c) Peak displacements on the top of tower number 3

FIGURE 12: Effects of variations in damping coefficient and velocity exponent of the viscous fluid dampers on the seismic responses of the contrast model.

control effects of the multitower cable-stayed bridge with the partially longitudinal constraint system are very different from the fully floating system. In the partially longitudinal constraint system, the design objective of seismic control using viscous fluid dampers is to yield maximum reductions in the base shears and moments of bridge towers longitudinally restricted with the bridge deck, with hampering the significant gain achieved in the base shears and moments of bridge towers longitudinally unrestricted with the bridge deck. However, in the fully floating system, the design objective of seismic control using viscous fluid dampers is to yield maximum reductions in the displacements on the top of bridge towers and displacements at two ends of bridge deck, with hampering the significant gain achieved in the base shears of all bridge towers.

\section{Multiobjective Optimization Design of Viscous Fluid Damper}

4.1. Multiobjective Optimization Problem. The optimization design of seismic control with passive dampers is necessary for practical application $[15,16]$. As for the optimization design of the multitower cable-stayed bridge with the fully floating system, the optimized parameters $c$ and $\alpha$ of the viscous fluid dampers can be easily determined from Figure 12. As shown in Figure 12, for the values of damping coefficient $c=16000$ and velocity exponents $\alpha=0.8$, the maximum reductions in the displacement on the top of tower number 3 , displacement at the left end of bridge deck, and base moment of tower number 3 can be approximately obtained with very slight increase in the base shear of tower number 3 . Table 2 
TABLE 2: Seismic control effects of the multitower cable-stayed bridge with the fully floating system.

\begin{tabular}{|c|c|c|c|}
\hline Control objective & Uncontrolled response, $f_{0}$ & Controlled response, $f_{1}$ & Relative variation, $\left(f_{0}-f_{1}\right) \times 100 \% / f_{0}$ \\
\hline Base shear of tower number $3\left(\times 10^{3} \mathrm{kN}\right)$ & 53.518 & 55.824 & $-4.31 \%$ \\
\hline Base moment of tower number $3\left(\times 10^{6} \mathrm{kN} \cdot \mathrm{m}\right)$ & 3.4155 & 2.4119 & $29.38 \%$ \\
\hline Displacement on the top of tower number $3(\mathrm{~m})$ & 0.6008 & 0.1351 & $77.51 \%$ \\
\hline Displacement at the left end of bridge deck (m) & 0.7023 & 0.2463 & $64.93 \%$ \\
\hline
\end{tabular}

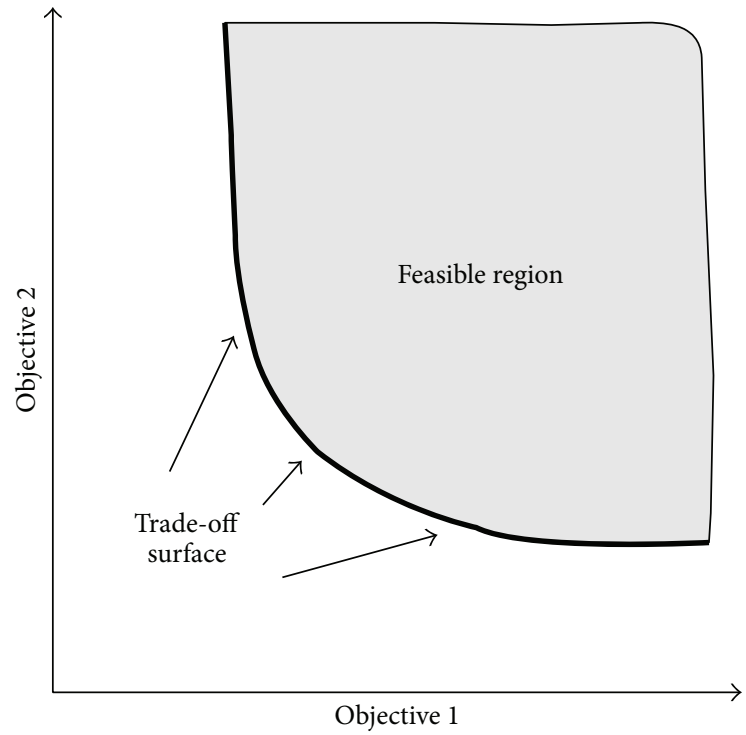

FIGURE 13: Trade-off between two competing objectives [17].

further shows the seismic control effects using the values of damping coefficient $c=16000$ and velocity exponents $\alpha=$ 0.8 .

However, as shown in Figures 7-10, individual optimal solutions for each control objective are obviously different for the multitower cable-stayed bridge with the partially longitudinal constraint system using viscous fluid dampers. For example, it is impossible to meet minimum base forces of bridge towers longitudinally restricted with the bridge deck and minimum base forces of bridge towers longitudinally unrestricted with the bridge deck simultaneously. Thus, none of the optimal solutions allows simultaneous optimizations for the base forces of all of bridge towers, which indicates that multiobjective optimization is necessary to obtain acceptable solutions.

Multiobjective optimization provides a family of equally valid solutions (Pareto optimal solutions) rather than a single optimal solution. As shown in Figure 13, a tradeoff exists between the objectives such that an improvement in one objective cannot be achieved without detriment to another [17]. In the case of seismic control of the multitower cable-stayed bridge with the partially longitudinal constraint system, a trade-off exists between the base forces of bridge towers longitudinally restricted with the bridge deck and base forces of bridge towers longitudinally unrestricted with the bridge deck as mentioned previously. The nondominating sort genetic algorithm II (NSGA-II), which is well-adopted in multiobjective optimization, is used in the present study. Deb et al. [18] have proposed an elitist, fast, and parameterfree multiobjective optimization genetic algorithm (NSGAII). Specific details of the NSGA-II can be referenced in Deb et al. [18].

4.2. NSGA-II-Optimized Parameters for Viscous Fluid Damper. In this section, the optimization design method based on the NSGA-II is proposed to determine the optimized parameters $c$ and $\alpha$ of the viscous fluid dampers for seismic control of the multitower cable-stayed bridge with the partially longitudinal constraint system. As discussed in Section 3.1, the optimization design objective is to yield maximum reductions in the base shears and moments of bridge towers longitudinally restricted with the bridge deck, with hampering the significant gain achieved in the base shears and moments of bridge towers longitudinally unrestricted with the bridge deck. Meantime, the unfavorable controlling effect on the displacements at two ends of bridge deck is also worthy of attention. Therefore, a summary of the objective functions used in this study is given in Table 3. The NSGA-IIbased optimization is performed, where the population size is taken to contain 20 individuals. An upper limit on the number of generations is specified to be 50 .

Five objectives introduced in Table 3 are used for multiobjective optimization and the number of nondominated individuals obtained after optimization is 12 . Pareto optimal fronts between different objectives are shown in Figure 14:

(i) As shown in Figures 14(a) and 14(b), the base shears and moments of bridge towers longitudinally restricted with the bridge deck are in competition with those of bridge towers longitudinally unrestricted with the bridge deck. Here, one set effectively controls the base shears and moments of bridge towers longitudinally restricted with the bridge deck but sacrifices control of base shears and moments of bridge towers longitudinally unrestricted with the bridge deck. Thus, there is no individual that can appropriately reduce base shears and moments of all of bridge towers. And the objectives $f_{2}$ and $f_{4}$ can be improved at the cost of the degraded objectives $f_{1}$ and $f_{3}$, respectively.

(ii) As shown in Figures 14(c) and 14(d), the base shear is in accordance with the base moment for individual bridge towers. Thus, the objectives $f_{1}$ and $f_{2}$ are equivalent to the objectives $f_{3}$ and $f_{4}$, respectively, for seismic control of the multitower cable-stayed bridge with the partially longitudinal constraint system. 
TABLE 3: Five objective functions.

\begin{tabular}{ll}
\hline Number & Description \\
\hline$f_{1}$ & Controlled base shear of tower number 1 that is normalized with respect to the uncontrolled base shear of tower number 1 \\
$f_{2}$ & Controlled base shear of tower number 2 that is normalized with respect to the uncontrolled base shear of tower number 2 \\
$f_{3}$ & $\begin{array}{l}\text { Controlled base moment of tower number } 1 \text { that is normalized with respect to the uncontrolled base moment of tower } \\
\text { number } 1\end{array}$ \\
$f_{4}$ & $\begin{array}{l}\text { Controlled base moment of tower number } 2 \text { that is normalized with respect to the uncontrolled base moment of tower } \\
\text { number } 2\end{array}$ \\
$f_{5}$ & $\begin{array}{l}\text { Controlled displacement at the left end of bridge deck that is normalized with respect to the uncontrolled displacement at } \\
\text { the left end of bridge deck }\end{array}$ \\
\hline
\end{tabular}

(iii) As shown in Figure 14(e), the objective $f_{1}$ degrades slightly with degradation in the objective $f_{5}$ up to a certain level and then the objective $f_{1}$ degrades significantly with the slight improvement in the objective $f_{5}$. And as shown in Figure 14(f), the objective $f_{2}$ improves significantly with degradation in the objective $f_{5}$ up to a certain level and then the objective $f_{1}$ improves slightly with the slight improvement in the objective $f_{5}$. Thus, considering the efficiency of seismic control, the objectives $f_{2}$ and $f_{4}$ can be improved significantly with the slight degradation in the objectives $f_{1}$ and $f_{3}$ when the objective $f_{5}$ reaches the maximum value, which means the displacement at the end of bridge deck reaches the maximum value. It should be noted that, for the partially longitudinal constraint system, the displacement at the end of bridge deck is still very small even if it reaches the maximum value.

In summary, for seismic control of the multitower cablestayed bridge with the partially longitudinal constraint system, a design engineer can choose a set of proper parameters $c$ and $\alpha$ of the viscous fluid dampers from Figure 14 which can satisfy the different performance requirements. Moreover, if an engineer wants to minimize base forces including base shear and moment of bridge towers longitudinally restricted with the bridge deck regardless of displacement of the bridge deck, the most appropriate parameters $c$ and $\alpha$ of the viscous fluid dampers can be selected as set A presented in Figure 14, where the objectives $f_{1}-f_{5}$ are $1.34,0.61,1.28,0.68$, and 1.22 , respectively, and the corresponding parameters $c$ and $\alpha$ of the viscous fluid dampers are 11600 and 0.38 , respectively.

It should be pointed out that earthquake and wind action are two main hazards for a multitower cable-stayed bridge. Thus, the multiobjective optimal control with respect to earthquake and wind action is very important. The dynamic responses and control effects of the multitower cable-stayed bridge subject to earthquake and wind action are significantly different. The question of multiobjective optimization with respect to different hazards in the life cycle will be addressed for future in-depth study. Furthermore, in the present work, the passive viscous fluid dampers are employed in the seismic control of the multitower cable-stayed bridge. During the process of earthquake, the parameters of the dampers cannot be changed, which results in the different control effects for different control objectives. This is why the multiobjective optimization control method is used to determine the parameters of the damper. In recent years, the control systems' progress has moved toward a more efficient and adaptable semiactive technology. For instance, a method of controlling in real time the hysteresis component in semiactive control systems is proposed to obtain the optimal mitigation [19]. Research in this area will be conducted in the future.

\section{Conclusions}

The performance of viscous fluid dampers for the earthquake protection of the Jiashao Bridge, a six-tower cablestayed bridge with the application of partially longitudinal constraint system under strong earthquake ground motions, is investigated in the present study. From the trend of the analytical results of the present work, the following conclusions are drawn:

(1) The differences in the longitudinal seismic responses of a multitower cable-stayed bridge using partially longitudinal constraint system and fully floating system are investigated. In the partially longitudinal constraint system, the base forces of bridge towers longitudinally unrestricted with the bridge deck and the displacements of the bridge deck and towers are relatively small. However, the base forces of bridge towers longitudinally restricted with the bridge deck are too large. In contrast, in the fully floating system, the displacements of the bridge deck and towers are too large and the base forces of all towers are relatively small.

(2) The differences in the seismic control effects using viscous fluid dampers for a multitower cable-stayed bridge with partially longitudinal constraint system and fully floating system are investigated. In the partially longitudinal constraint system, the installations of viscous fluid dampers are beneficial for the reductions in base forces of bridge towers longitudinally restricted with the bridge deck, with significant increases in the base forces of bridge towers longitudinally unrestricted with the bridge deck. Furthermore, the displacements on the top of bridge towers are found to be slightly reduced, with slight increases in the displacements at two ends of bridge deck. In contrast, in the fully floating system, the large displacements of the bridge deck and towers can be 


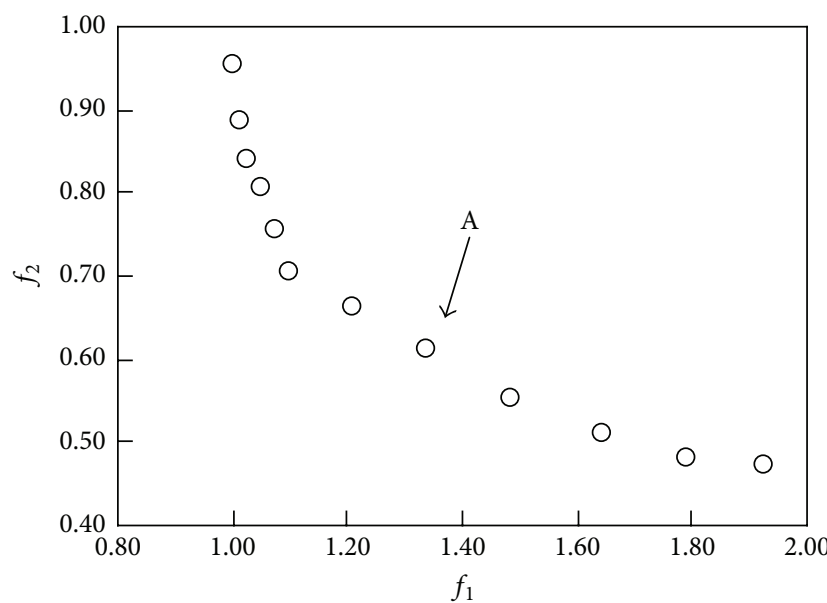

(a) $f_{1}-f_{2}$

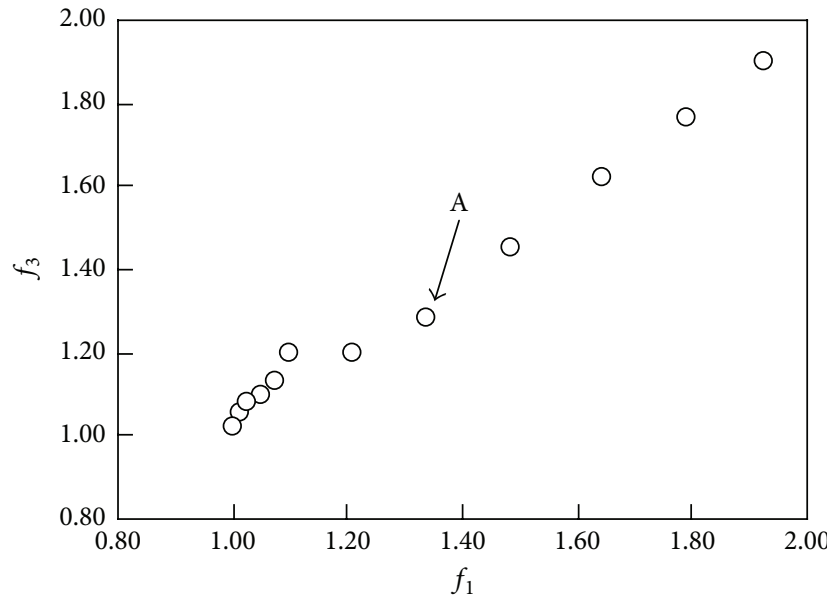

(c) $f_{1}-f_{3}$

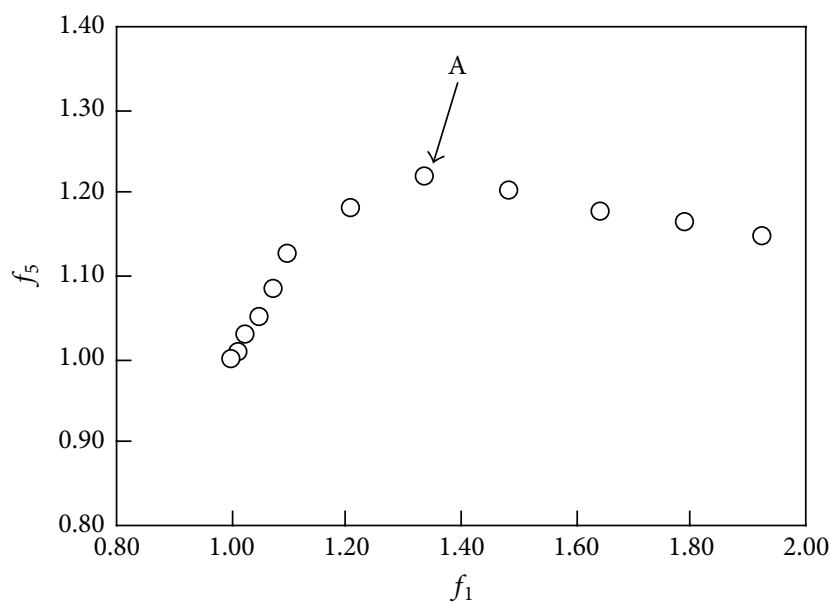

(e) $f_{1}-f_{5}$

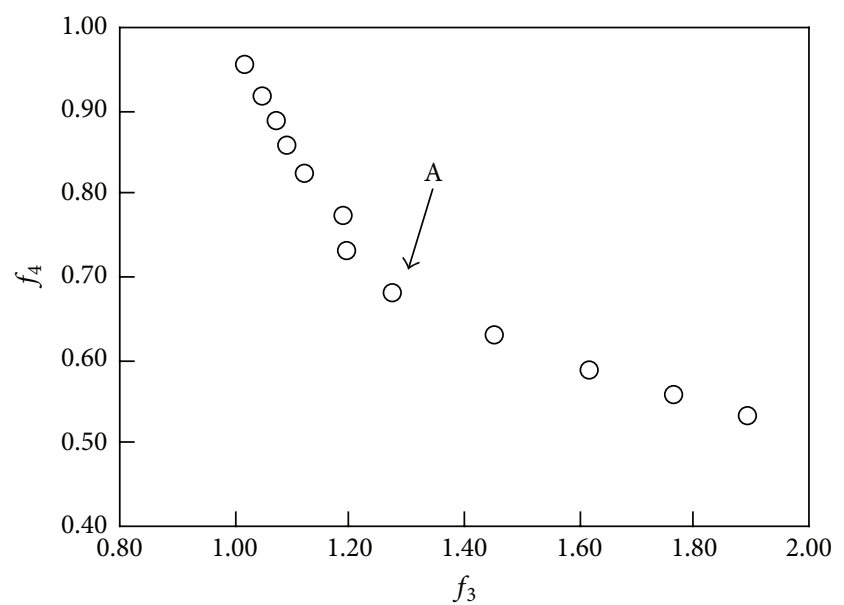

(b) $f_{3}-f_{4}$

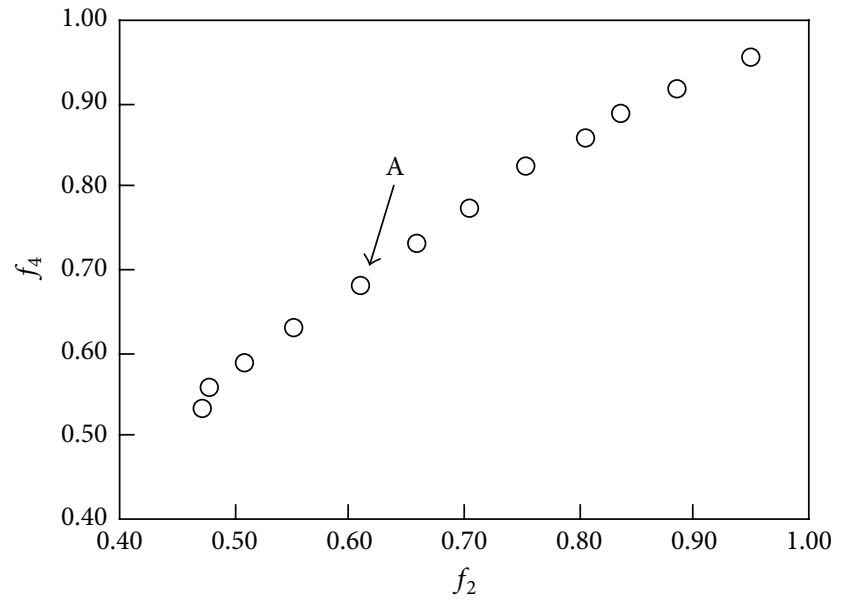

(d) $f_{2}-f_{4}$

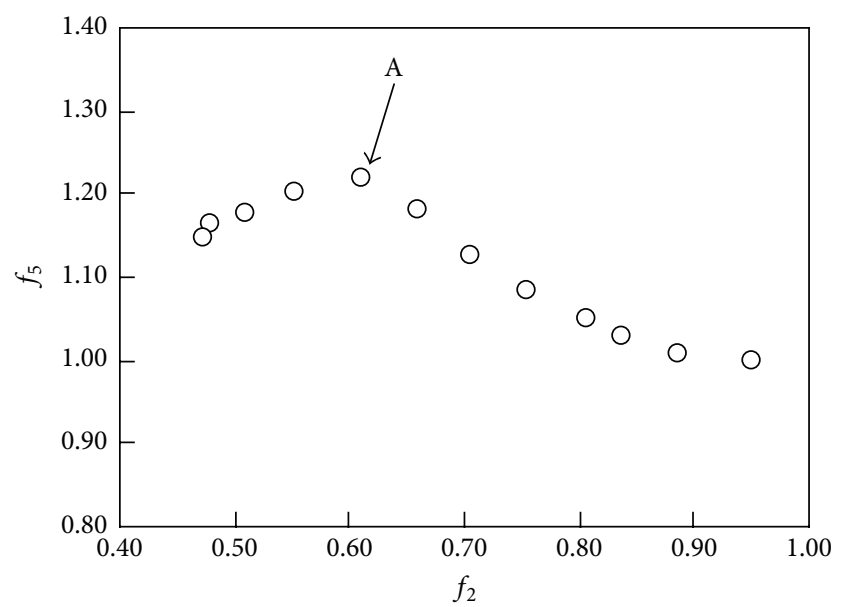

(f) $f_{2}-f_{5}$

FIGURE 14: Pareto optimal fronts.

significantly reduced using viscous fluid dampers. And the base moments of bridge towers are found to be also reduced reasonably, with increases in the base shears of bridge towers.
(3) A multiobjective optimization design method that uses a nondominating sort genetic algorithm II (NSGA-II) is used to optimize parameters of the viscous fluid dampers. Optimization results reveal that 
a design engineer can choose a set of proper parameters of the viscous fluid dampers from Pareto optimal fronts which can satisfy the different performance requirements. Moreover, considering the efficiency of seismic control, the most appropriate parameters of the viscous fluid dampers can be selected as when the displacement at the end of bridge deck reaches the maximum value, which can yield maximum reductions in the base forces of bridge towers longitudinally restricted with the bridge deck, with slight increases in the base forces of bridge towers longitudinally unrestricted with the bridge deck.

\section{Competing Interests}

The authors declare that there are no competing interests regarding the publication of this paper.

\section{Acknowledgments}

The authors gratefully acknowledge the National Basic Research Program of China (973 Program) (no. 2015CB060000), the National Natural Science Foundation of China (no. 51438002 and no. 51578138), and the Fundamental Research Funds for the Central Universities (no. 2242016K41066).

\section{References}

[1] Y. Q. Ni, J. Y. Wang, and L. C. Lo, "Influence of stabilizing cables on seismic response of a multispan cable-stayed bridge," Computer-Aided Civil and Infrastructure Engineering, vol. 20, no. 2, pp. 142-153, 2005.

[2] A. Camara, A. M. Ruiz-Teran, and P. J. Stafford, "Structural behaviour and design criteria of under-deck cable-stayed bridges subjected to seismic action," Earthquake Engineering and Structural Dynamics, vol. 42, no. 6, pp. 891-912, 2013.

[3] R. Zhou, Z.-H. Zong, X.-Y. Huang, and Z.-H. Xia, "Seismic response study on a multi-span cable-stayed bridge scale model under multi-support excitations. Part II: numerical analysis," Journal of Zhejiang University: Science A, vol. 15, no. 6, pp. 405418, 2014.

[4] M. Domaneschi and L. Martinelli, "Performance comparison of passive control schemes for the numerically improved ASCE cable-stayed bridge model," Earthquake and Structures, vol. 3, no. 2, pp. 181-201, 2012.

[5] O. E. Ozbulut, S. Hurlebaus, and R. Desroches, "Seismic response control using shape memory alloys: a review," Journal of Intelligent Material Systems and Structures, vol. 22, no. 14, pp. 1531-1549, 2011.

[6] A. Y. Fallah and T. Taghikhany, "Time-delayed decentralized $\mathrm{H}_{2} /$ LQG controller for cable-stayed bridge under seismic loading," Structural Control \& Health Monitoring, vol. 20, no. 3, pp. 354-372, 2013.

[7] W. Xie and L. Sun, "Passive hybrid system for seismic failure mode improvement of a long-span cable-stayed bridges in the transverse direction," Advances in Structural Engineering, vol. 17, no. 3, pp. 399-411, 2014.

[8] M. Domaneschi, "Feasible control solutions of the ASCE benchmark cable-stayed bridge," Structural Control \& Health Monitoring, vol. 17, no. 6, pp. 675-693, 2010.
[9] H. Iemura and M. H. Pradono, "Advances in the development of pseudo-negative-stiffness dampers for seismic response control," Structural Control \& Health Monitoring, vol. 16, no. 7-8, pp. 784-799, 2009.

[10] H. Li, J. Liu, and J. Ou, "Seismic response control of a cablestayed bridge using negative stiffness dampers," Structural Control \& Health Monitoring, vol. 18, no. 3, pp. 265-288, 2011.

[11] W.-L. He and A. K. Agrawal, "Passive and hybrid control systems for seismic protection of a benchmark cable-stayed bridge," Structural Control and Health Monitoring, vol. 14, no. 1, pp. 1-26, 2007.

[12] Y. Fujino and D. Siringoringo, "Vibration mechanisms and controls of long-span bridges: a review," Structural Engineering International, vol. 23, no. 3, pp. 248-268, 2013.

[13] F. Geng, Y. Ding, and A. Li, "Passive control system for mitigation of longitudinal buffeting responses of a six-tower cable-stayed bridge," Mathematical Problems in Engineering, vol. 2016, Article ID 6497851, 18 pages, 2016.

[14] Z. Q. Lang, P. F. Guo, and I. Takewaki, "Output frequency response function based design of additional nonlinear viscous dampers for vibration control of multi-degree-of-freedom systems," Journal of Sound and Vibration, vol. 332, no. 19, pp. 44614481, 2013.

[15] S. E. Abdel Raheem and T. Hayashikawa, "Energy dissipation system for earthquake protection of cable-stayed bridge towers," Earthquake and Structures, vol. 5, no. 6, pp. 657-678, 2013.

[16] Y. Murakami, K. Noshi, K. Fujita, M. Tsuji, and I. Takewaki, "Simultaneous optimal damper placement using oil, hysteretic and inertial mass dampers," Earthquake and Structures, vol. 5, no. 3, pp. 261-276, 2013.

[17] H.-S. Kim and P. N. Roschke, "Fuzzy control of base-isolation system using multi-objective genetic algorithm," ComputerAided Civil and Infrastructure Engineering, vol. 21, no. 6, pp. 436-449, 2006.

[18] K. Deb, A. Pratap, S. Agarwal, and T. Meyarivan, "A fast and elitist multiobjective genetic algorithm: NSGA-II," IEEE Transactions on Evolutionary Computation, vol. 6, no. 2, pp. 182197, 2002.

[19] M. Domaneschi, "Simulation of controlled hysteresis by the semi-active Bouc-Wen model," Computers and Structures, vol. 106-107, pp. 245-257, 2012. 


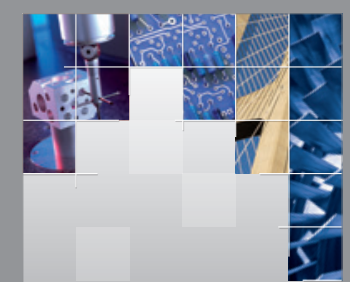

\section{Enfincering}
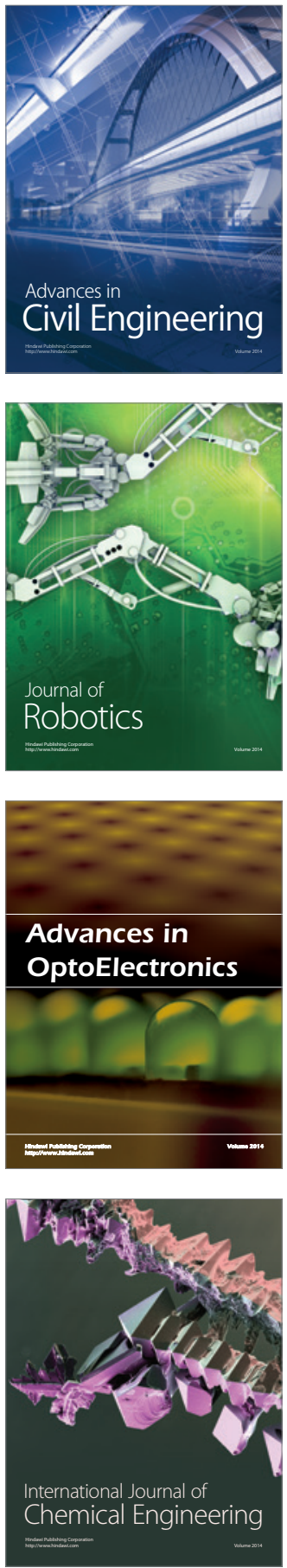

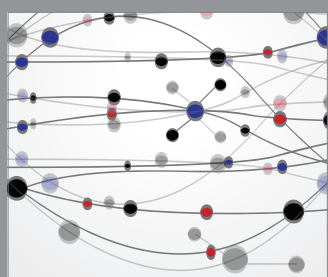

The Scientific World Journal

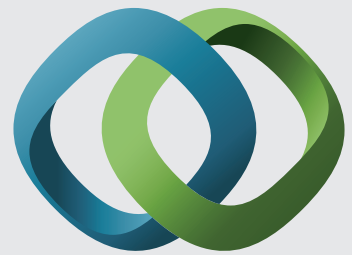

\section{Hindawi}

Submit your manuscripts at

http://www.hindawi.com
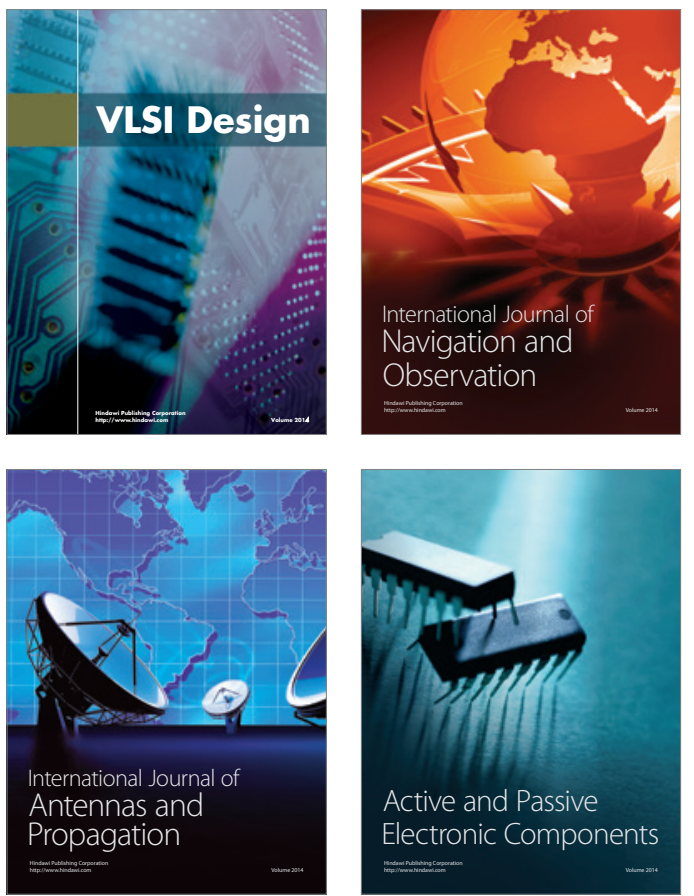
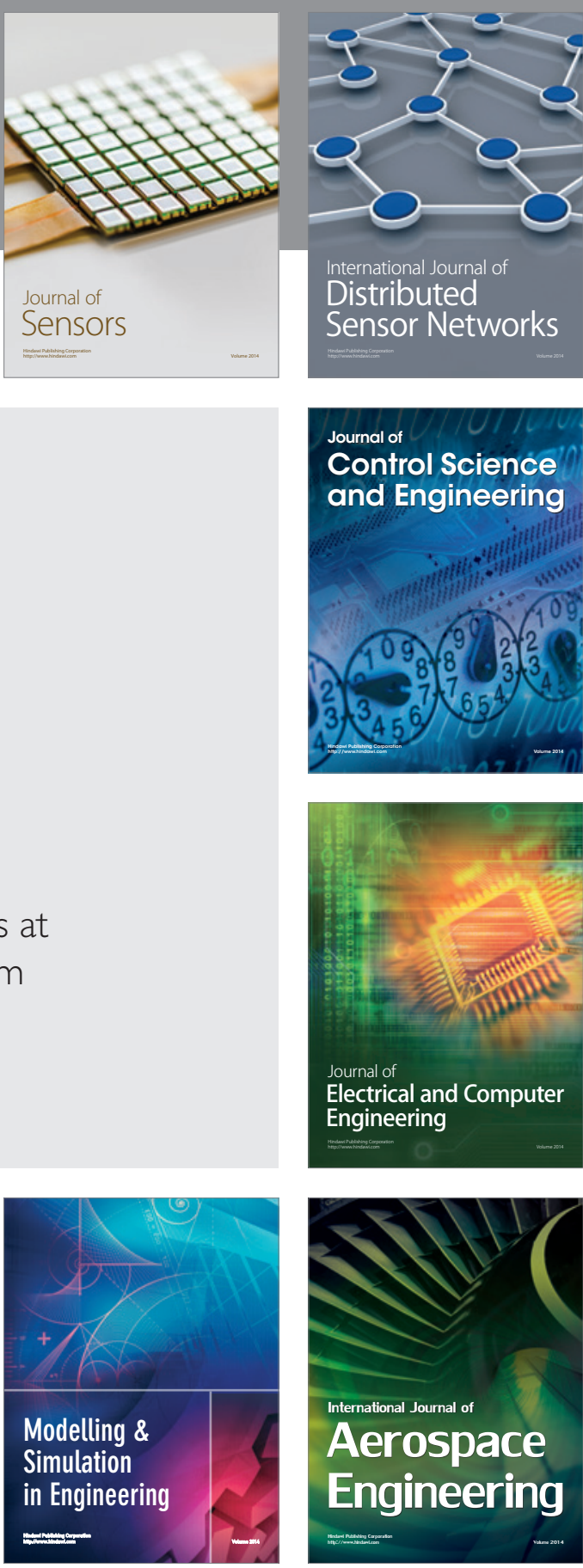

International Journal of

Distributed

Sensor Networks

Journal of

Control Science

and Engineering
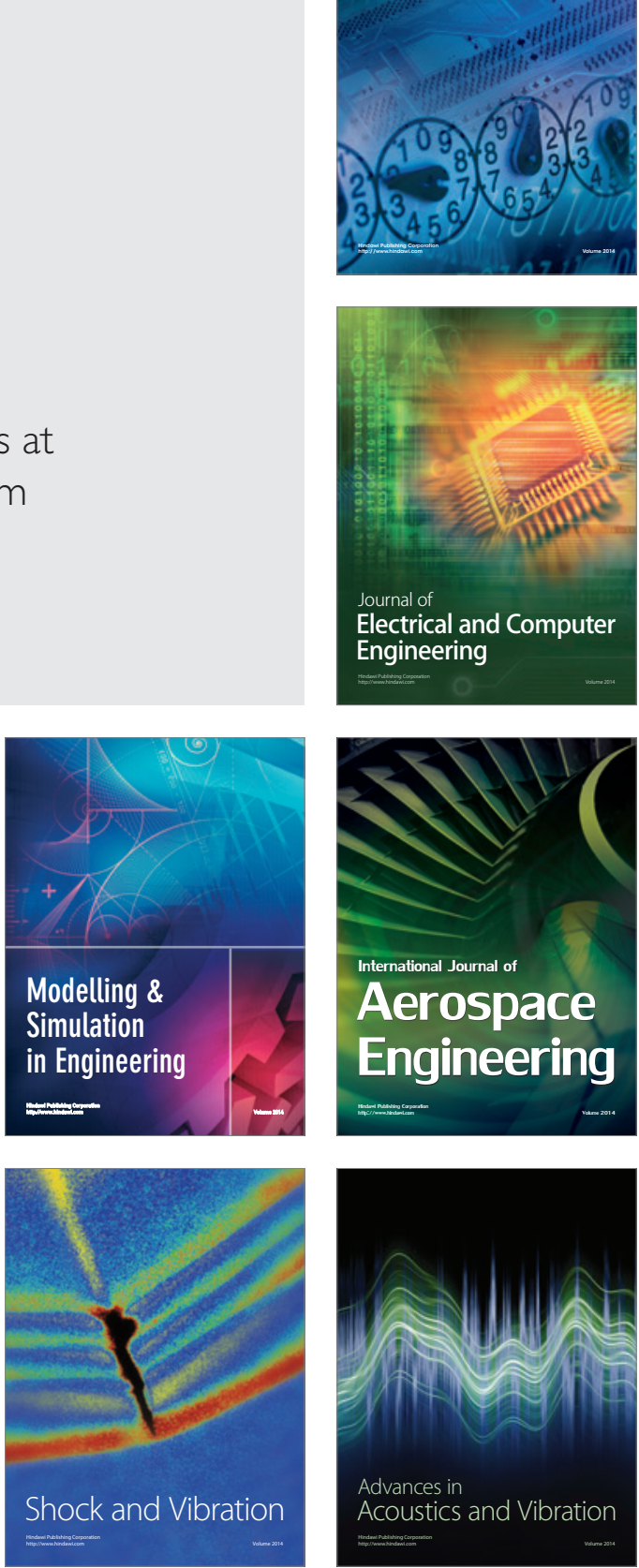